\title{
ALÉM DE RAWLS: ALGUMAS CRÍTICAS DE AMARTYA SEN SOBRE IMPARCIALIDADE, EQUIDADE E LIBERDADES
}

\section{BEYOND RAWLS: SOME CRITICAL REFLECTIONS OF AMARTYA SEN ABOUT IMPARTIALITY, FAIRNESS AND LIBERTIES}

\section{Leonam Liziero ${ }^{1}$}

RESUMO: O presente trabalho analisa alguns aspectos mais basilares da teoria da Justiça de John Rawls, sob a perspectiva dicotômica entre Justiça Transcendental e Justiça Comparativa, esboçada por Amartya Sen. Os dois prismas analisados no artigo são a ideia de liberdade de Rawls e o caráter transcendental de sua teoria derivados de sua abordagem contratualista, na qual pessoas unem-se voluntariamente em um plano hipotético com um propósito de obter benefícios maiores que conseguidos de forma isolada. A partir da racionalidade das partes com um desinteresse pessoal e com um interesse geral garantidos por um hipotético véu da ignorância gera os princípios necessários para uma sociedade justa, que somente pode ser alcançada com a constituição de uma sociedade politicamente estruturada. Neste contexto, Sen analisa os problemas nessa concepção formula outra na qual a relação entre a instituição política e o comportamento individual real é vital para uma completa concepção de justiça.

Palavras-chave: John Rawls; Justiça; Imparcialidade

ABSTRACT This paper analyzes some more fundamental aspects of the theory of justice of John Rawls, under the dichotomous perspective between Transcendental Justice and Comparative Justice, sketched by Amartya Sen. The two prisms will be analyzed in the article, within the idea of liberty of Rawls and the transcendental character of his theory derived from a contractarian approach, in which people come together voluntarily in a hypothetical plane with a purpose of getting benefits greater than achieved in an isolated manner. Starting from the rationality of the parties with a personal disinterest and a general interest secured by a hypothetical veil of ignorance generates the necessary principles for a fair society, which can only be achieved with the creation of a politically structured society. In this context, Sen analyzes problems in this conception and elaborates another e in which the relationship between political institutions and the real individual behavior is vital to a complete conception of justice. Keywords: John Rawls; Justice; Impartiality.

\section{INTRODUÇÃO}

\footnotetext{
${ }^{1}$ Doutorando e Mestre em Teoria e Filosofia do Direito pela Universidade do Estado do Rio de Janeiro - UERJ. Professor da Universidade Candido Mendes - UCAM. Advogado. E-mail: leonamliziero@gmail.com. Versão em português recebida em 19/08/2014, aceita em 21/10/2014, e autorizada para publicação em 29/06/2015
} 
Em sua obra Uma Teoria da Justiça, publicada originalmente em 1971, Rawls propõe uma concepção política de justiça, sob o aspecto procedimental e deontológico, com fortes bases liberais e conferindo importância à distribuição de bens. Uma defesa de um Estado com características liberais, democráticas e com um planejamento econômico de bem-estar social. Com uma pretensão universalista, o liberalismo igualitário de Rawls argumenta a legitimidade de uma sociedade cujas normas jurídicas procuram seguir uma concepção de justiça baseada em uma escolha racional e ao mesmo tempo desinteressada. Rawls denomina sua teoria como justiça como equidade.

Em resposta a essa teoria, diversas ideias fervilharam no cenário da filosofia política desde a publicação desta obra de Rawls e com ela dialogando diretamente. Suas críticas basicamente vão a dois sentidos. Em um primeiro pode-se destacar a vertente libertária, cujo principal expositor foi Robert Nozick. Em sua obra de 1974, Anarquia, Estado e Utopia, Nozick apresenta uma rejeição ao Estado intervencionista na economia e na vida do indivíduo e defende um minimalismo estatal. Em outra vertente, encontram-se o heterogêneo grupo denominado comunitarista, que se opõem ao universalismo rawlsiano. Destacam-se a crítica ao liberalismo deontológico de Rawls feita por Michael Sandel em Liberalismo e os Limites da Justiça de 1982; ao individualismo feita por Charles Taylor, que geraria um atomismo social e ao esvaziamento da ideia de virtude detectada por Alasdair Macintyre em seu livro Depois da Virtude de 1981, procurando um telos que constitui um bem para a humanidade dentro de sua comunidade.

Amartya Sen é um dos mais interessantes críticos a Rawls. Enquanto Rawls defende uma justiça transcendental emitida por um arranjo institucional, dependendo assim de uma série de suposições para que sua teoria possa ter efetividade, Sen parte de outro ponto de partida, de uma justiça comparativa, crucial para a reflexão sobre alguns problemas que a teorias transcendentais de justiça não alcançam.

\section{A JUSTIÇA COMO EQUIDADE NA ABORDAGEM CONTRATUALISTA}


Conforme disserta Rawls, as ideias de justiça e de equidade são necessariamente vinculadas. E deve ter como pressuposto a equidade como uma diretriz normativa. As pessoas devem assim priorizar a busca por uma justiça política por meio de sua razoabilidade e abandonar interesses pessoais. Este é um dos pressupostos do hipotético contrato social rawlsiano, a posição original.

Rawls resgata a teoria do contrato social, desenvolvida por teóricos da modernidade como Hobbes, Locke e Kant. Seguindo método parecido, Rawls elabora uma situação hipotética, um estado de natureza muito mais abstrato que seus filósofos influenciadores e o denomina por posição original. Assim como seus antecessores, há um encontro de vontades de seres racionais em uma situação de plena igualdade na busca de um propósito, que na teoria de Rawls é estabelecer uma concepção de justiça. Essa concepção de justiça é formada por meio de uma espécie de contrato social, o chamado pelo autor de acordo original, que cria vínculos obrigatórios entre essas partes e torna cogente a concepção de justiça para a instituição política.

O método contratualista é "adequado para justificar o poder jurídico público e as obrigações de obediência com ele ligadas, porque ele representa a forma fundamental de um negócio político no qual da liberdade surgem obrigatoriedades com força jurídica” (HÖFFE, 2006, p. 402). Billier (2005, p. 147) observa que "o contrato é um procedimento dialético no qual a totalidade das liberdades individuais naturais converge para o Estado, que vai redistribuílas consagradas com o selo do direito positivo". Conforme a lição de Ubiratan de Macedo, o contrato de Rawls é uma situação hipotética que permite a cada pessoa signatária decidir em um exercício reflexivo seus objetivos dentro da sociedade. Nesse sentido:

O contrato social é uma situação puramente hipotética, destinada a estabelecer um princípio de justiça social para a sociedade a ser instaurada. Na posição ou situação original, as pessoas pactuam, sem conhecerem sua futura posição de classe na sociedade, ou seu status, ou a parte que lhe caberá na distribuição dos bens e das capacidades naturais, ou sua psicologia pessoal. (MACEDO, 1995, p. 89)

Na posição original, o abstrato estado de natureza rawlsiano, as pessoas dotadas da imparcialidade garantida pelo véu da ignorância decidem quais seriam os princípios que devem nortear uma sociedade justa. A concepção do que é justo, segundo Rawls (2008, p. 164), "é um conjunto de princípios, gerais na forma e universais na aplicação, que deve ser publicamente Versão em português recebida em 19/08/2014, aceita em 21/10/2014, e autorizada para publicação em 29/06/ 


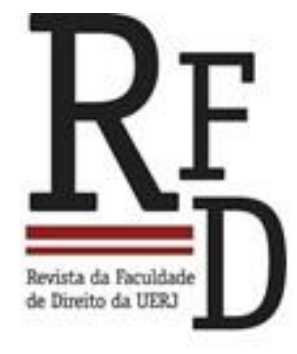

REVISTA DA FACULDADE DE DIREITO DA UERJ- RFD, N. 27, 2015

reconhecido como última instância de apelação para a ordenação das reivindicações conflitantes de pessoas morais". A racionalidade das pessoas na condição de razoabilidade, concluem pelos dois princípios de justiça. A partir da escolha destes dois princípios, haveria uma determinação das instituições políticas que se coadunariam com estes dois princípios.

A justiça, manifestada por meio de instituições justas, corresponderia aos dois princípios, que por sua vez seguem uma ordem lexical. Tanto a ordem lexical como os princípios em si são frutos da racionalidade das hipotéticas pessoas signatárias do contrato social na posição original.

Rawls durante toda sua obra apoia sua concepção de justiça em dois princípios, cujo conteúdo vai se transmutando com o avanço do livro, conforme vai abordando alguns novos dilemas na estruturação de uma sociedade justa, desde a especulação sobre eles no Capítulo II de Uma Teoria da Justiça até o Capítulo V, no qual ele discute a distribuição de bens e apresenta enunciados mais refinados destes princípios.

O primeiro e mais primordial deles, conhecido por princípio da liberdade igual, é definido da seguinte forma por Rawls (2008, p. 376): "Cada pessoa deve ter um direito igual ao mais abrangente sistema total de liberdades básicas iguais que sejam compatíveis com um sistema similar de liberdades para todos". Basicamente, esse princípio determina que uma liberdade somente possa ser restringida em nome de outra liberdade, nunca para outros propósitos, como uma melhoria social geral na sociedade ou uma redistribuição de bens. Rawls, influenciado pela ética deontológica de Kant, não concebe que seria justa uma sociedade na qual o indivíduo tivesse seus direitos e liberdades solapados pelo Estado em nome de um bemestar geral. Raciocínios como esse levariam ao pensamento utilitarista que é combatido pelo autor desde o início de sua obra.

O raciocínio dele é que em na posição original, as partes ao deliberarem sobre a concepção de justiça, não optariam por uma sociedade na qual suas liberdades poderiam ser comprimidas em nome de uma felicidade ou interesse maior. Deste modo, como na posição original as partes não tem ideia qual será o papel a ser ocupado posteriormente, sua racionalidade levaria os signatários a formularem que independentemente de qualquer que seja a sociedade, as liberdades deveriam estar asseguradas, somente podendo ser restritas quando Versão em português recebida em 19/08/2014, aceita em 21/10/2014, e autorizada para publicação em 29/06/ 2015 
seu exercício entrar em conflito com outra liberdade de outro indivíduo. De acordo com Alvaro de Vita (1999, p.42), “a prioridade das liberdades fundamentais tem o sentido de exprimir, na estrutura básica da sociedade, o respeito mútuo que os cidadãos devem ter pelas formas de vida e pelas concepções do bem uns dos outros.".

Verifica-se também que para Rawls, a justiça determina que o sujeito seja inviolável enquanto ser livre, o que refletirá na escolha do primeiro princípio e em consequência em uma preocupação do próprio autor em criticar o utilitarismo. Neste sentido, "A prioridade da liberdade significa que, sempre que as liberdades fundamentais podem ser de fato instituídas, não é permitido trocar uma liberdade menor ou desigual por uma melhoria do bem-estar econômico" (RAWLS, 2008, p. 185). Comenta nesse sentido Sandel (2012, pp.189) que os signatários insistiriam na supremacia desse princípio sobre qualquer ideia de bem-estar da sociedade. Nenhum sujeito racional na posição original sacrificaria direitos e liberdades fundamentais para melhorias sociais e econômicas.

Por sua vez o segundo princípio é uma decorrência do primeiro e se relaciona com a justa distribuição de bens e de igualdade de oportunidades no acesso aos cargos públicos. Rawls admite que naturalmente desigualdades sociais e econômicas possam existir em uma sociedade justa, mas da forma mais mitigada possível. O segundo princípio, dividido em duas partes, é uma forma de contrabalancear essas desigualdades, que devem ser arranjadas para que: "(a) se estabeleçam para o máximo benefício possível dos menos favorecidos que seja compatível com as restrições do princípio de poupança justa, como (b) estejam vinculados a cargos e posições abertos a todos em condições de igualdade equitativa de oportunidades" (RAWLS, 2008, p. 376)

Esse caráter distributivo se dá pela chamada regra maximin, ou seja, a maximização prioritária dos benefícios aos menos favorecidos. Explica Alvaro de Vita (1999, p.48): “é preferível um arranjo institucional que garanta um quinhão maior em termos absolutos, ainda que não igual, de bens primários para todos, do que um outro no qual uma igualdade de resultados é assegurada à custa de reduzir as expectativas de todos." De acordo com esse segundo princípio, a distribuição deve ser realizada de forma que melhore a situação de pessoas em posições socioeconômicas diferentes de forma igualitária, todavia sempre que houver a 
melhora para os de melhor posição necessariamente deve haver melhora aos menos favorecidos naturalmente. No sistema rawlsiano a igualdade de distribuição não deve ser de forma alguma absoluta, porque é inerente à sociedade a desigualdade natural, por fatores econômicos ou habilidades inerentes ao indivíduo. Para Morrison (2012, p. 473), "Rawls está tentando equilibrar a necessidade de crescimento de riqueza, com o respeito aos menos favorecidos na sociedade. [...] Rawls considera seus princípios básicos de justiça, baseados também num respeito deontológico pela autonomia, como conforme, à maximização". Ao se preocuparem com a posição social ou a quantidade de riqueza que poderia estar disponível, os signatários adotam esse segundo princípio, de maneira que mesmo se foram menos favorecidos na sociedade, possam receber bens e terem oportunidades iguais.

A distribuição dada pela loteria natural não pode ser considerada justa ou injusta. $O$ fato de alguém nascer inteligente ou com dificuldade de aprendizado, rico ou pobre, não é uma questão de justiça, são fatos naturais, dependem do arbítrio da natureza. O que é um problema de justiça, especialmente de justiça política é a forma como o Estado e suas instituições tratam essas desigualdades. Por isso, ao pactuarem sobre a concepção de justiça a ser adotada, "os homens concordam em só se valer dos acidentes da natureza e das circunstâncias sociais quando resulta em benefício comum. Os dois princípios são um modo equitativo de enfrentar a arbitrariedade" (RAWLS, 2008, p. 122) Quando escreve sobre o raciocínio que levariam as partes na posição original a adotarem os dois princípios, Rawls argumenta:

A estrutura básica da sociedade deve permitir essas desigualdades, contanto que melhorem a situação de todos, inclusive a dos menos favorecidos, e desde que selas sejam igualmente compatíveis com a liberdade igual e a igualdade de oportunidades. Já que as partes começam por uma divisão igual de todos os bens primários sociais, os que se beneficiam tem, por assim dizer, um poder de veto. Chegamos assim ao princípio da diferença. Tomando-se a igualdade como base da comparação, os que ganharam mais devem tê-lo feito em condições justificáveis para os que os que ganharam menos. (RAWLS, 2008, p. 185).

Rawls explica que a racionalidade das partes do contrato é resultante de um desinteresse mútuo na escolha de princípios que garantiriam o maior número de bens primários possíveis, protegendo especialmente sua liberdade. Mesmo sem ter conhecimento de qual será sua posição na sociedade, as partes no exercício de sua racionalidade escolheriam os dois princípios formulados. Em suas palavras, 
As pessoas que se encontram na posição original tentam reconhecer princípios que promovam seu sistema de objetivos da melhor forma possível. Para isso, tentam garantir para si mesmas o mais alto índice de bens primários sociais, já que isso lhes possibilita promover sua concepção do bem da maneira mais eficaz, seja qual for essa concepção. (RAWLS, 2008, p.175)

Neste esboço do início da teoria da justiça como equidade, é interessante notar que a justiça somente pode ser alcançada dentro de um arranjo institucional político. Assim, somente se pode falar em justiça ao se considerar a sociedade e sua estruturação política. Na leitura de Gargarella (1999, p.35), "dicho contrato tiene como objetivo último el establecimiento de ciertos princípios básicos de justicia. Estes principios, sin embargo, no se orientan a resolver casos particulares, problemas cotidianos de justicia."

Rawls é bem preciso neste ponto, ao definir que o principal objeto da justiça é a estrutura básica da sociedade, "ou o modo como as principais instituições sociais distribuem os direitos e deveres fundamentais e determinam a divisão das vantagens decorrentes da cooperação social." (RAWLS, 2008, p.8). Estrutura básica, no sentido defendido, é "um sistema de normas públicas que define um esquema de atividades que conduz os homens a agirem juntos a fim de produzir um total maior de benefícios e atribui a cada um deles certos direitos reconhecidos a uma parte dos ganhos." (RAWLS, 2008, p.102).

A concepção de justiça é uma concepção política de justiça. Somente na organização da sociedade a justiça pode ser manifestada. Uma vez constatado isto, a preocupação da justiça como equidade é desenhar uma estrutura social que possa ser correspondente a uma ideia de justiça transcendental resultante de uma razão imparcial, de um equilíbrio entre exigências conflitantes.

\section{IMPARCIALIDADE, ESCOLHA RACIONAL E LIBERDADE}

A equidade está indissociável da imparcialidade. Rawls assim pressupõe que no exercício da racionalidade dos signatários cobertos pelo véu da ignorância e atendendo à equidade, o resultado seria os princípios que formam a concepção de justiça.

Como Rawls argumenta, em uma situação em que indivíduos dotados de razão querem chegar a um objetivo comum, a escolha deve ser pautada em uma gama de opções possíveis, sempre com seu prévio conhecimento dessas possibilidades, carregando seus interesses Versão em português recebida em 19/08/2014, aceita em 21/10/2014, e autorizada para publicação em 29/06/ 2015 


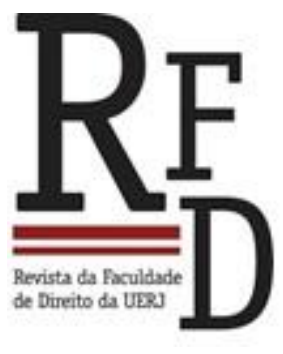

REVISTA DA FACULDADE DE DIREITO DA UERJ- RFD, N. 27, 2015

particulares na tomada da decisão. A tendência natural do choque entre esses interesses é de um equilíbrio entre eles, que não necessariamente levaria a uma condição justa. Apesar de ser uma teoria procedimental pura, a justiça como equidade considera grande importância à questão dos sentimentos morais colocados na deliberação dos diversos pontos de vista, o que gera a defesa dos diversos interesses particulares e a transferência disso para o espaço comum não seria nada além de uma ação invasiva de convencimento de alguns interesses em detrimentos de outros.

Desta forma, se na posição original fossem escolhidos princípios que não os rawlsianos, a justiça poderia ser ainda como equidade. Outras concepções de justiça são passíveis de serem defendidas porque podem ser o resultado do equilíbrio dos interesses na posição original. Aqui pode ser identificado um primeiro problema, já que o acordo original de Rawls pressupõe a escolha não só necessariamente dos dois princípios como também da ordem lexical em que são organizados.

Para evitar que haja um embate interminável sobre que concepção de justiça deve ser adotada - uma vez que se imagina que cada pessoa racional que conheça sua situação de vida defenda uma concepção que lhe possa beneficiar - a justiça como equidade trabalha com o cooperativismo social, já que a sociedade tende a ser um engajamento de vantagens mútuas. Nesta seara contratualista, além de se pensar em um vínculo obrigacional político dado pelo acordo, deve-se considerar os benefícios e sacrifícios que a adesão à determinada sociedade causaria no individuo. Portanto, há um importante cooperativismo na sociedade a ser levado em conta, no qual todos os indivíduos pertencentes devem contribuir de alguma forma e se beneficiarem de forma proporcional, já que "reconhecem claramente que não podem conseguir o que desejam sem a cooperação dos outros. Assim, o comportamento cooperativo é escolhido como uma norma de grupo para o benefício de todos". (SEN, 2011, p. 236) Todavia, na defesa de seus pontos de vista particulares, os signatários de um acordo original procurariam uma forma de maximizar seus benefícios e minimizar suas contribuições. Neste ínterim, alguma teoria que saísse como resultado desta parcialidade geraria uma circunstância política injusta. A importância do uso do véu da ignorância como mecanismo busca pela imparcialidade se baseia em uma idealização cooperativista na qual as pessoas no acordo original não saibam suas próprias condições na sociedade e que desta forma consigam pensar em uma concepção de justiça por meio de um equilíbrio reflexivo em condições de justiça. 
O véu cumpre sua função metafísica de forma a proporcionar a imparcialidade para a ponderação de juízos. Assim, conforme a explicação de Rawls,

\begin{abstract}
Interpreta-se o véu da ignorância de forma a significar não apenas que as partes não tem conhecimento de seus objetivos e fins individuais (exceto o que está contido na fraca teoria do bem), mas também que a evidencia histórica lhes é inacessível. Não sabem, e não tem como enumerar, as circunstâncias sociais nas quais se encontram, ou a variedade de técnicas que sua sociedade possa ter à disposição. Não tem, portanto, nenhuma fundamentação objetiva para confiar em determinada distribuição probabilística e não em outra, e não é possível recorrer ao princípio da razão insuficiente como modo de contornar essa limitação (RAWLS, 2008, p.225).
\end{abstract}

Com tal artifício, segundo argumenta Rawls, é possível manter a imparcialidade na escolha de uma concepção de justiça. Essa concepção de justiça deve levar em conta o cooperativismo entre os signatários originais, de forma que todos concordem em um sistema que possa oferecer vantagens e sacrifícios que não prejudiquem demasiadamente algum indivíduo. Neste sentido, a concepção de justiça deve ser pensada levando-se em conta que as partes não conhecem sua própria condição dentro da sociedade devido ao véu da ignorância, o que permitira que as partes deliberassem com interesses comuns, ao mesmo tempo em que seus particulares interesses seriam impedidos de serem defendidos porque há um desconhecimento a este respeito.

As partes só saberiam sua posição social quando o véu da ignorância fosse retirado. Assim, necessário seria pensar nesta posição original em uma concepção de justiça que pudesse não beneficiar o máximo possível, mas sim que fosse oferecesse menos riscos. A parte, ao raciocinar sobre que princípios de justiça deveriam nortear aquela sociedade, não sabe seu gênero, sua etnia, sua classe social, sua comunidade religiosa, suas aptidões físicas e mentais e o tempo de sua sociedade, seu estágio civilizatório ou cultural. A parte não sabe de nada desses elementos, mas conhece seus conceitos. Além do mais, "os únicos fatos específicos que as partes conhecem é que sua sociedade está sujeita às circunstâncias de justiça e a qualquer consequência que decorram disso". (RAWLS, 2009, p. 167)

Isso gera algumas que Rawls formula baseado nas teorias da justiça então existentes e argumenta a favor de seus dois princípios de justiça. No caso do utilitarismo, corrente teórica de maior adversidade para o autor, as partes não concordariam com uma sociedade cuja concepção de justiça fosse utilitária para satisfazer o máximo de expectativas de uma maioria Versão em português recebida em 19/08/2014, aceita em 21/10/2014, e autorizada para publicação em 29/06/ 
da sociedade. As partes, em seu desinteresse mútuo, não optariam uma sociedade que tivesse como diretriz a justiça dada pela maximização do prazer de uma maioria em detrimento de uma minoria. O caminho que leva a este raciocínio é que, como as partes desconhecem sua situação na sociedade, poderiam pertencer a uma minoria política ou social que teria seus direitos limados em favor dos interesses de uma maioria. Da mesma forma, uma sociedade cuja concepção de justiça permitisse discriminações raciais ou de gênero não seriam jamais acordadas na posição original.

No argumento a favor de seus dois princípios da justiça, Rawls (2009, p. 186) defende a relação entre eles e a regra maximin, ou seja, a regra na qual se adota uma alternativa cujo pior resultado possível seja melhor que os piores resultados das outras. A regra maximin parece ser uma proteção que as partes tem contra as arbitrariedades de um outro tipo de método de escolha, ainda que não necessariamente esperem sempre ter uma situação menos favorecida.

A opção pela regra maximin na tomada de decisão da concepção de justiça tem três características que são admissíveis (RAWLS, 2009, p. 188). A primeira é a que esta regra não leva em conta as circunstancias possíveis. O véu da ignorância impediria que as partes conseguissem fazer estatísticas a respeito de seus possíveis lugares na sociedade, o que fortaleceria o desinteresse mútuo na manifestação de cada vontade. A segunda característica é que os signatários não são tendentes a se arriscar por um ou outro benefício a mais, já que o risco implicado na possibilidade de um ganho pode ser uma perda de grande parte de coisas mais importantes. Neste caso qualquer um que tivesse uma racional aversão por riscos demasiados adotaria a regra maximin. A terceira característica considera as alternativas rejeitadas de concepções de justiça seriam dificilmente aceitas ou intoleráveis para as partes.

Na suposição do produto da racionalidade imparcial dos signatários do contrato social na posição original, o primeiro princípio seria o da liberdade igual. Conforme o conceito deste princípio formulado por Rawls (2008, p.73), “cada pessoa deve ter um direito igual ao sistema mais extenso de liberdades fundamentais que seja compatível com um sistema similar de liberdades para outras pessoas". De acordo com o primeiro princípio, as instituições devem ser organizadas de forma que as liberdades fundamentais dos indivíduos não possam ser tolhidas. Na concepção defendida por Rawls,

A liberdade é um padrão de convivência determinado por formas sociais. O primeiro princípio requer simplesmente que certos tipos de leis, aquelas que definem as Versão em português recebida em 19/08/2014, aceita em 21/10/2014, e autorizada para publicação em 29/06/ 2015 
liberdades fundamentais, se apliquem igualmente a todos e permitam a mais abrangente liberdade compatível com uma liberdade semelhante para todos. A única razão para restringir as liberdades fundamentais e torná-las menos extensas é que, se isso não fosse feito, interfeririam umas com as outras. (RAWLS, 2008, p.74).

Conforme explica Morrison (2012, p. 471), “os que estão por trás desse véu escolheriam a liberdade como seu primeiro princípio, uma vez que, desconhecendo a situação real ou a sua própria concepção do bem-viver, isso lhes daria um maior oportunidade de perseguir quaisquer ideais que prefiram". Ainda conforme Michael Sandel (2012, p. 188), “insistiríamos na supremacia desse princípio sobre qualquer tentativa de maximização de bem-estar geral. Não sacrificaríamos nossos direitos e liberdades fundamentais em prol de benefícios sociais ou econômicos".

Observa-se que a instituição política justa pressupõe não só uma prioridade em relação aos dois princípios, mas também numa necessária ordem de preferência nas possíveis contradições entre o primeiro e o segundo princípio. A ponderação entre esses dois princípios na filosofia rawlsiana se volta a favor do primeiro, o que evidencia uma raiz liberal em seu pensamento. Nesse caso, leciona Marrone (2005, p.499):

\footnotetext{
O próprio ordenamento lexicográfico dos princípios, ou seja, o fato de que o princípio de liberdade seja prioritário em relação ao princípio da diferença - é uma maneira de formular uma axiologia dos princípios estruturada de modo tal que, por exemplo, uma restrição de liberdade seja compatível somente com a salvaguarda da liberdade, mas não com a extensão do bem-estar social ou com a maior eficiência das instituições.
}

Para Höffe (2006, p. 290), "Rawls defende uma prevalência do primeiro princípio (direitos e liberdades) sobre o segundo princípio (chances, rendimento e bem-estar). Com isto, ele reconhece a (absoluta) prioridade dos objetos não-econômicos sobre os econômicos." A defesa do liberalismo político de Rawls se evidencia na prevalência das liberdades sobre questões de distribuição de bens. Ainda que a justiça como equidade seja uma teoria igualitária, fica nítida em caso de embates sobre prioridades, a supremacia do indivíduo sobre o Estado ou a comunidade. O indivíduo, sujeito racional, formula um Estado baseado em dois princípios de justiça para o qual a segurança de direitos e liberdades é preferível a uma distribuição de bens em detrimento de daqueles. 
REVISTA DA FACULDADE DE DIREITO DA UERJ- RFD, N. 27, 2015

\section{JUSTIÇA COMPARATIVA E INCOMPLETUDE}

A partir desta concepção de justiça formulada por Rawls, Sen inicia suas críticas. Inicialmente, para que todo o sistema rawlsiano de justiça se estruture, é necessário considerar que as partes teriam que necessariamente chegar aos dois princípios após um debate mutualmente desinteressado. Se as partes chegassem a outro resultado mesmo com a imparcialidade, a raiz da teoria de Rawls é atingida.

Sen (2010, p. 88) identifica um problema neste primeiro ponto, em que "a imparcialidade pode assumir muitas formas diferentes e ter manifestações bastante distintas". Neste raciocínio, a imparcialidade pode se manifestar em uma concepção de justiça em que os princípios não seriam necessariamente os que Rawls identificou como os melhores para serem diretrizes de instituições justas.

Sen exemplifica esta alternatividade de abordagens com o método do espectador imparcial de Smith, em que pode existir uma concepção de justiça que não se aplicaria ao espectador, e ainda sim seria desinteressada. Enquanto a abordagem do véu da ignorância faz com que os representantes sejam os representados após a retirada do véu, o espectador de Smith não participa de "qualquer exercício como um contrato baseado em grupo. Não existe nenhum grupo contratante, e não há nenhuma insistência de que os avaliadores precisem ser coerentes com o grupo afetado" (SEN, 2011, p.90). Neste contexto, seria possível uma justiça como equidade mesmo sem a posição original e, consequentemente, sem que a concepção de justiça se baseasse nos dois princípios.

Uma vez havendo a escolha dos dois princípios, ainda sim há problemas como são prescritos. A prioridade total da liberdade é um deles. Rawls prioriza de forma extremada a prevalência das liberdades fundamentais. Desta forma, a liberdade pessoal deve ser mais importante em um arranjo institucional de justiça do que as garantias que possibilitem as pessoas a exercerem a liberdade? Esta é uma das críticas mais contundentes que Sen faz ao caráter transcendental da teoria da justiça de Rawls, que é incapaz de individualizar as situações - principalmente no tocante à distribuição de bens - e assim, efetivamente, realizar a justiça. Sen por isso prefere um método de justiça comparativa.

A abordagem das capacidades se concentra na vida humana e não apenas em alguns objetos separados de conveniência, como rendas ou mercadorias que uma pessoa pode possuir, que muitas vezes são considerados, principalmente na análise econômica,

Versão em português recebida em 19/08/2014, aceita em 21/10/2014, e autorizada para publicação em 29/06/ 
como o principal critério do sucesso humano. Na verdade, a abordagem propõe um sério deslocamento desde a concentração nos meios de vida até as oportunidades reais de vida. Isso também ajuda a provocar uma mudança desde as abordagens avaliativas orientadas para os meios, principalmente focando no que John Rawls chama de bens primários, que são muito úteis para vários propósitos, como renda e riqueza, poderes e prerrogativas associados a cargos, as bases sociais da autoestima, e assim por diante. (SEN, 2011, pp. 267-268)

Seguindo as reflexões de Sen de forma muito breve, observamos que Rawls não se preocupou com a efetividade da justiça, ou melhor, não se preocupou em teorizar como justiça poderia ser realizada no mundo real. Partindo do pressuposto de uma antiga concepção do direito indiano da qual Sen se vale para explicar pontos de sua teoria, a justiça como equidade rawlsiana atenderia apenas à niti e ignoraria a nyaya. Seria uma teoria da justiça que não oferece respostas de aplicabilidade, ou ainda, que apesar das instituições correspondentes aos princípios de justiça, não seria capaz de evitar injustiças na sociedade.

As expressões niti e nyaya derivam da filosofia do direito indiano e são usadas por Amartya Sen para caracterizar a justiça transcendental abrangente de ideal de comportamento e a material de concretização, sendo que as duas palavras tem um sentido de justiça. Assim, "os papeis das instituições, regras e organizações, importantes como são, tem de ser avaliados da perspectiva mais ampla e inclusiva de nyaya, que está inevitavelmente ligada ao mundo que de fato emerge, e não apenas às instituições ou regras que por acaso temos." (SEN, 2011, p.50)

A teoria de Rawls depende de um comportamento ideal das pessoas, mas que não leva em conta o comportamento real. A concepção de justiça baseada nos dois princípios "não resolve esse problema se a teoria da justiça procurada precisa ter algum tipo de aplicabilidade para orientar a escolha das instituições nas sociedades reais" (SEN, 2011, p.98). Novamente, mais um motivo pelo qual Sen entende ser insuficiente uma abordagem teórica da justiça de forma puramente transcendental.

Outro aspecto a ser destacado sobre a insuficiência da abordagem transcendental é a questão da incompletude em teorias da justiça, tal qual na justiça como equidade rawlsiana. “A admissibilidade da incompletude discutida anteriormente, em uma forma tentativa ou assertiva, é parte da metodologia de uma disciplina que pode permitir e facilitara a utilização de pontos de vista de espectadores imparciais de longe e de perto" (SEN, 2011, pp.161-162)

Contrário à ideia de totalidade de teorias da justiça, como a de Rawls, Sen defende que 


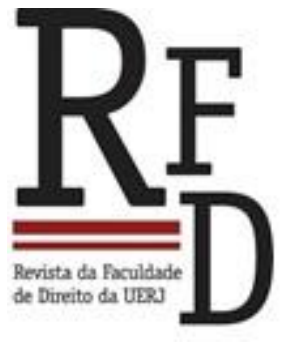

REVISTA DA FACULDADE DE DIREITO DA UERJ- RFD, N. 27, 2015

a incompletude é uma característica importante que deve estar presente em uma teoria da justiça. A incompletude justamente trata das situações em que a justiça como resultado de um acordo pleno não oferece resposta. Para tais teorias, uma situação de incompletude é um sinal de fracasso. Todavia é importante lembrar que são tais incompletudes que permitem verificar a possibilidade de teorias como a de Rawls. Por isso, "a aceitabilidade da incompletude avaliativa é sem dúvida um assunto central em toda teoria de escolha social e é relevante para as teorias da justiça também” (SEN, 2011, p.136) Assim, a incompletude em uma teoria de justiça possibilita uma abordagem comparativa com o intuito de reduzir as injustiças existentes.

\section{LIBERDADES SUBSTANCIAIS E CRÍTICAAO PROCEDIMENTALISMO}

A liberdade formal priorizada por Rawls, assim como sua concepção de bens primários a serem possuídos pelas pessoas, não são capazes de atender ao problema nem do exercício de liberdades, nem da individualidade em si do ser humano.

Conforma observa Sen, uma das formas de se efetivar a justiça é a consideração de como a pessoa vai conseguir escolher seus objetivos de vida. Diferentemente de Rawls, Sen se preocupa com as características pessoais que tornam possível a conversão de bens primários em realizações. Assim, a liberdade não pode ser exercida somente com a distribuição de bens primários como renda e riqueza. Estas capacidades de conversão são as liberdades substantivas, as mais cruciais liberdades que o ser humano possui. Explica Alvaro de Vita (2008) que "o que essa noção de capacidade objetiva captar é a liberdade que uma pessoa tem de escolher entre diferentes modos de vida que ela pode considerar valiosos".

Sen neste contexto explica a importância das liberdades para o ser humano, que as colocam como primordiais em comparação com as instrumentais:

\footnotetext{
As liberdades individuais substantivas são consideradas essenciais. (..) Ter mais liberdade para fazer as coisas que são justamente valorizadas é (1)importante por si mesmo para a liberdade global da pessoa e (2) importante porque favorece a oportunidade de a pessoa ter resultados valiosos. (...) Ter mais liberdade melhora o potencial das pessoas para cuidar de si mesmas e para influenciar o mundo, questões centrais para o processo de desenvolvimento (SEN, 2010, p.33)
} 
Notemos que estas liberdades substantivas tem um foco teórico não-transcendental. Neste caso, "a capacidade é um tipo de liberdade: a liberdade substantiva de realizar combinações alternativas de funcionamentos" (SEN, 2010, p.105). É uma preocupação claramente realística. No pensamento de Sen, o desenvolvimento humano está intrinsecamente relacionado à liberdade, uma vez que a liberdade possibilita o desenvolvimento.

No entendimento do filósofo indiano, a teoria da justiça como equidade "implica uma simplificação drástica e formulista de uma tarefa enorme e multifacetada" (SEN, 2011, p.100) A relação entre os arranjos institucionais e o comportamento individual real é vital para uma completa concepção de justiça, o que para Sen, a teoria da justiça como equidade não consegue responder.

Outro problema decorrente do primeiro é a abordagem contratualista, que Rawls procura resgatar em um raciocínio com influências de Kant. A posição original de Rawls é o momento em que as partes, cobertas pelo véu da ignorância, realizam um contrato cujo resultado unânime é a concepção de justiça baseada em seus dois princípios. Pode ser "definida de modo a ser um status quo no qual todos os acordos firmados são justos. [...] Assim, a justiça como equidade pode usar a ideia de justiça procedimental pura desde o início" (RAWLS, 2008, p.146). A abordagem de Rawls pressupõe que as partes estariam desinteressadas e que ao final do acordo original, elas se sentiriam seguras em retirar o véu e acordarem no mundo real porque independentemente da posição social que ocupassem, o arranjo institucional seria justo porque a concepção de justiça resultante do acordo seria justa.

Essa noção de justiça procedimental pura se aproxima de ideia de justiça como equidade na medida em que nesta, segundo Rawls, o conceito de justo precede o conceito de bem; e, naquela, a correção do processo e a sua justeza precede também a importância ou as qualificações possíveis dos seus resultados. Como apontado na ideia de justiça como equidade, as instituições dependem de seus processos de funcionamento - de sua justiça processual - e os princípios da justiça como equidade devem assegurar a estabilidade destas instituições justas.

$\mathrm{Na}$ leitura de Kolm, a posição original tem um caráter utilitarista, identificando um problema na racionalidade advinda do equilíbrio reflexivo, criticando a forma peculiar de contratualismo proposta por Rawls. Ao verificar o produto da convergência das vontades dos signatários na posição original, Kolm argumenta que "o resultado obtido tem uma forma Versão em português recebida em 19/08/2014, aceita em 21/10/2014, e autorizada para publicação em 29/06/ 2015 
utilitarista, mas não pode realmente ser utilitarismo, pois este é uma teoria da ética social, e o resultado obtido a partir de uma teoria da posição original que, como vimos, não pode ser uma teoria da ética social”.(KOLM, 2000, p.245)

Tal abordagem pressupõe que uma equidade caracterizada como imparcialidade, ou desinteresse, seria alcançada somente com o acordo original. Esta pressuposição de Rawls evidentemente leva a refletir e questionar se realmente o acordo original, nas condições e nas limitações formais que Rawls destaca, poderia efetivamente ter como resultado a equidade. Caso os argumentos propostos por Rawls sejam suficientes para demonstrar a possibilidade de se alcançar a equidade no acordo original, resta saber se é método mais adequado.

Esta limitação da abordagem contratualista permitiu que Sen propusesse o método do espectador imparcial de Smith como alternativa a dialogar com a teoria de Rawls. Apresenta uma abordagem alternativa utilizando aspectos da teoria de Adam Smith. Esta abordagem de Smith é relevante para Sen, pois

\footnotetext{
é capaz de levar em conta possibilidades que a abordagem do contrato social não pode facilmente acomodar [...] É a perspectiva firmemente 'aberta' invocada pelo 'espectador imparcial' de Adam Smith que pode precisar de reafirmação nos dias de hoje. Ela pode fazer uma diferença substancial para nossa compreensão das exigências de imparcialidade na filosofia moral e política no mundo interconectado em que vivemos. (SEN, 2011, p.183)
}

Amartya Sen entende que o contratualismo é limitado por não considerar a inclusão de sociedades diversas. Na posição original, as partes não consideram a existência de outras sociedades, pois os destinatários dos princípios de justiça são eles próprios. Não se considera assim que um a justiça seja pensada por alguém fora de determinada sociedade. Este isolamento influencia as partes na posição original, pois os valores da sociedade em questão representam um interesse de um determinado povo em um determinado fator espaço-temporal. Nisso, "o procedimento das 'posições originais' segregadas, operando como dispositivo isolado, não é propício para garantir um escrutínio adequadamente objetivo das convenções sociais e sentimentos paroquiais que podem influenciar as regras escolhidas na posição original” (SEN, 2011,p. 157).

\section{CONSIDERAÇÕES FINAIS}

Versão em português recebida em 19/08/2014, aceita em 21/10/2014, e autorizada para publicação em 29/06/ 
Rawls, ainda que defenda a possiblidade de se alcançar a justiça enquanto equidade na estruturação do arranjo institucional, não oferece solução no comportamento entre sociedades e entre pessoas de diferentes sociedades.

Tendo em vista algumas limitações do método contratualista para análise comportamental, Sen demonstra que é necessário repensar a teoria de Rawls no que diz respeito à relevância das perspectivas globais. A existência de outros Estados e consequentemente de diversos arranjos institucionais é um fator de alta relevância para a estrutura de uma sociedade.

A limitação da abordagem contratualista assim se manifesta na aplicação da concepção de justiça somente dentro de uma sociedade, como se fosse um ente isolado, o que em no mundo real nos parece ser impossível. Neste sentido, é visto que Rawls consegue formular uma teoria da justiça baseada em um preceito de equidade. Tal teoria representa um marco na filosofia política do Século XX e uma revisita ao contratualismo e à abordagem transcendental.

$\mathrm{Na}$ formulação da justiça como equidade, o primeiro princípio, que trata sobre a liberdade, é prioritário na formulação de uma estrutura básica da sociedade justa. Para tal, é imprescindível que em uma sociedade justa, sejam assegurados mecanismos de garantias das liberdades individualizantes, em uma acepção mais ampla que o pensamento liberal clássico de proteção à propriedade privada.

Indo além das crenças do jusnaturalismo, Rawls concebe a liberdade não como um direito natural e sim como direito humano criado artificialmente pra se assegurar as prioridades que os homens entenderiam em uma sociedade justa. É o resultado de uma escolha racional em prol do desenvolvimento pessoal em condições igualitárias dentro do possível A abordagem contratualista é limitada e não oferece respostas para a realização da justiça material em uma efetiva conversão dos bens primários em capacidades reais, ainda que haja um consenso sobre a desigualdade justa na medida de fornecer uma melhor situação os menos favorecidos.

Algumas questões posteriores da crítica à sua teoria da justiça possibilita uma reflexão sobre problemas tais como a necessidade da vinculação da justiça a uma abordagem transcendental que influi no comportamento das pessoas destinatárias, se a abordagem transcendental é suficiente para uma concepção de justiça, como a equidade pode ser alcançada e o porquê ela é um fator inerente à justiça, e finalmente, como se é possível ou não determinarmos concepções de justiça na estruturação de uma determinada sociedade sem um Versão em português recebida em 19/08/2014, aceita em 21/10/2014, e autorizada para publicação em 29/06/ 
REVISTA DA FACULDADE DE DIREITO DA UERJ- RFD, N. 27, 2015

compromisso com "os olhos da humanidade".

\section{REFERÊNCIAS}

BARRETTO, Vicente. O Fetiche dos Direitos Humanos e outros temas. 2 ed. Porto Alegre: Livraria do Advogado, 2013.

BILLIER, Jean-Cassien; MARYIOLI, Aglaé. História da Filosofia do Direito. Trad. Maurício de Andrade. Barueri: Manole, 2005.

CHÂTELET, François. História da Filosofia: Ideias, doutrinas. Vol 5. Trad. Guido de Almeida. Rio de Janeiro: Zahar Editores, 1974.

FARAGO, France. A Justiça. Trad. de Maria José Pontieri. Barueri: Manole, 2004

HÖFFE, Otfried. Justiça Política. Trad. Ernildo Stein. São Paulo: Martins Fontes, 2006.

KANT, Immanuel. Fundamentação da Metafísica dos Costumes. Trad. Tania Maria Bernkopf [et al]. São Paulo: Abril Cultural, 1983. (Os Pensadores)

KOLM, Serge-Christophe. Teorias modernas da justiça. São Paulo: Martins Fontes, 2000

MACEDO, Ubiratan Borges de. Liberalismo e Justiça Social. São Paulo: Ibrasa, 1995.

MARRONE, Pierpaolo. As tentativas de uma nova fundação: neoliberalismo, neocontratualimo e comunitarismo. In: DUSO, Giuseppe. O Poder: História da Filosofia Política Moderna. Trad. Andrea Ciacchi [et. al.] Petrópolis: Vozes, 2005

MORRISON, Wayne. Filosofia do Direito: dos gregos ao pós-modernismo. São Paulo: Martins Fontes, 2006.

NOVAIS, Jorge Reis. Contributo para uma teoria do Estado de Direito: do Estado de Direito Liberal ao Estado Social e Democrático. Lisboa, Almedina, 2006.

NOUR, Soraya. À Paz Perpétua de Kant: Filosofia do Direito Internacional e das Relações Internacionais. São Paulo: Martins Fontes, 2004.

RAWLS, John. Justiça como equidade: uma reformulação. São Paulo: Martins Fontes, 2003. . O Liberalismo Político. Trad. Dinah de Abreu Azevedo. 2 ed. São Paulo: Ática, 2000. . The Law of Peoples: with The Idea of Public Reason Revisited. Harvard University Press: Cambridge, 1999 


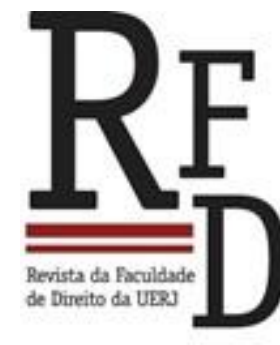

REVISTA DA FACULDADE DE DIREITO DA UERJ- RFD, N. 27, 2015

. Uma Teoria da Justiça. Trad. Jussara Simões. São Paulo: Martins Fontes, 2008

SCANLON, T.M. Contractualism and Utilitarism. In: DARWALL, Stephen. Contractarianism,

Contractualism. Oxford: Blackwell Publishers, 2003

SEN, Amartya. A Ideia de Justiça. Trad. Denise Bottmann. São Paulo: Companhia das Letras, 2011

Desenvolvimento como Liberdade. Trad. Laura Teixeira Mota. São Paulo:

Companhia das Letras, 2010

VITA, Álvaro de. A justiça igualitária e seus críticos. São Paulo: Unesp, 2002.

. O liberalismo igualitário: sociedade democrática e justiça internacional.

São Paulo: Martins Fontes, 2008. 